\title{
Anatomy and physiology of coronary blood flow
}

\author{
Heinrich R. Schelbert, MD, PhD
}

\section{INTRODUCTION}

Regional myocardial blood flow can now be measured noninvasively in units of milliliters blood per minute per gram myocardium. These noninvasive measurements are not confined to a specific imaging modality but are available with MRI, CT, and PET, although, thus far, most investigations of the coronary circulation in humans have employed PET flow measurements. Flow estimates with these different imaging modalities were found in animal experiments to correlate well with invasive flow estimates by the arterial blood sampling-microsphere technique widely considered as the "gold standard" of flow measurements. ${ }^{1-11}$ In these comparison studies, noninvasively-derived estimates corresponded linearly with invasively-measured myocardial blood flows over a wide flow range, i.e., from as low as $0.3 \mathrm{~mL} / \mathrm{minute} / \mathrm{g}$ to as high as $5-6 \mathrm{~mL} /$ minute $/ \mathrm{g}$. When tested in the human heart, noninvasive flow estimates correlated well with those obtained through invasively-obtained indices of flow and its changes by well-established alternate measurement approaches. ${ }^{12-16}$ Development and commercial availability of userfriendly software programs have facilitated the use of these new measurement capabilities so that they are now readily available in the clinical environment for the study of patients with cardiovascular disease.

As several investigations have indicated, measurements of myocardial blood flow at rest contain only limited diagnostic information. For example, even in patients with advanced cardiovascular disease such as nonischemic dilated or ischemic cardiomyopathy,

From the Department of Molecular and Medical Pharmacology, David Geffen School of Medicine at UCLA, University of California at Los Angeles, Los Angeles, CA.

Reprint requests: Heinrich R. Schelbert, MD, PhD, Department of Molecular and Medical Pharmacology, David Geffen School of Medicine at UCLA, University of California at Los Angeles, B2-085J CHS, 650 Charles E. Young Drive South, Los Angeles, CA 90095; hschelbert@ mednet.ucla.edu.

J Nucl Cardiol 2010;17:545-54.

$1071-3581 / \$ 34.00$

Copyright (c) 2010 The Author(s). This article is published with open access at Springerlink.com

doi:10.1007/s12350-010-9255-x hypertrophic cardiomyopathy, or coronary artery disease, resting myocardial blood flows frequently are similar to those in normal individuals. ${ }^{17-19}$ It is the response of myocardial blood flow to specifically-targeted pharmacological or physiological interventions that can uncover the presence of functional or structural disease-related alterations of the coronary circulation. This then underscores the need for closely examining these targets and how they relate to anatomical and functional determinants of coronary blood flow and, by inference, to myocardial blood flow and their alterations in cardiovascular disease. Local and systemic mechanisms regulate the complex interactions between flow and anatomy in order to meet the heart's energy needs. A comprehensive description of the coronary circulatory function and its control exceeds the scope of this review so that the interested reader is referred to detailed reviews on this topic..$^{20,21}$ This review then seeks to describe in broad strokes the major functional and anatomical determinants of coronary blood flow as they pertain to noninvasive measured myocardial blood flows.

\section{DETERMINANTS OF MYOCARDIAL BLOOD FLOW}

Conceptually, the coronary circulation can be divided into two compartments, the large epicardial conduit vessels and the resistance vessels, typically less than $300 \mu \mathrm{m}$ in diameter (Figure 1). Whereas the conduit vessels exert little if any resistance to flow, resistance to flow progressively rises as the vessel diameter of the resistance vessels declines from about $300 \mu \mathrm{m}$ in the small arteries to less than $100 \mu \mathrm{m}$ in the arteriolar vessels. ${ }^{20,21}$ Exchange of substrates between blood and tissue occurs at the level of the capillaries.

Flow across the myocardium largely depends on the pressure gradient between the aortic root (the "coronary driving pressure") and the right atrium. Under normal conditions, the driving pressure is fully maintained along the epicardial conduit vessels with little if any pressure loss in the distal epicardial arteries. However, intra-coronary pressures decline along the microvasculature (with most of the pressure dissipating in the 300-100 $\mu \mathrm{m}$ diameter vessels) until reaching a pressure 


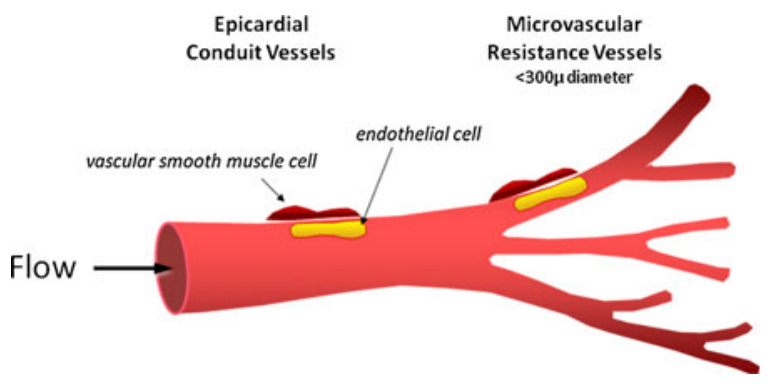

Figure 1. Highly schematic depiction of the main anatomic features of the coronary circulation (see text).

of $20-30 \mathrm{mmHg}$, still adequate to ascertain a gradient across the capillaries. Additional determinants of the resistance to flow include extravascular resistive forces that are directly related to the left ventricular systolic pressure, the contractile state of the myocardium and the heart rate.

Auto-regulatory mechanisms coordinate the interaction between intra-coronary driving pressure and microvascular resistance in order to maintain adequate flow across the capillaries for substrate delivery and removal. Through this mechanism (also defined as “coronary autoregulation"), decreases in driving pressure are compensated for by decreases in resistance and conversely, increases in driving pressure by increases in resistance so that flow remains constant for a given cardiac workload. This regulatory mechanism operates within the range of physiologic arterial pressures but fails during hypotension when flows become strongly dependent on the driving pressure. ${ }^{22}$

Changes in myocardial work and, thus, in energy demand, are accompanied by proportionate changes in coronary and, thus, myocardial blood flow. For example, as shown with noninvasive PET measurements, a 2.8 -fold increase in cardiac work (estimated from the rate pressure product) with supine bicycle exercise was matched by a 2.2 -fold increase in flow. ${ }^{23}$ Similarly, dobutamine infusion in patients with coronary artery disease raised the rate pressure product by a factor of 2.2 that was paralleled by a 2.4 -fold increase in flow in myocardial territories subtended by normal coronary arteries (Figure 2). ${ }^{24}$

Work-related flow increases are initiated by a metabolically-mediated decrease in microvascular resistance, possibly involving adenosine as a metabolite of adenosine monophosphate and causing vascular smooth muscle relaxation. The resulting flow increase is augmented by endothelium-dependent factors; higher flow velocities exert greater shear-stress upon the endothelium with stimulation of the endothelial nitric oxide synthase (eNOS) and release of the smooth musclerelaxing nitric oxide (NO). In this scenario, endothelial

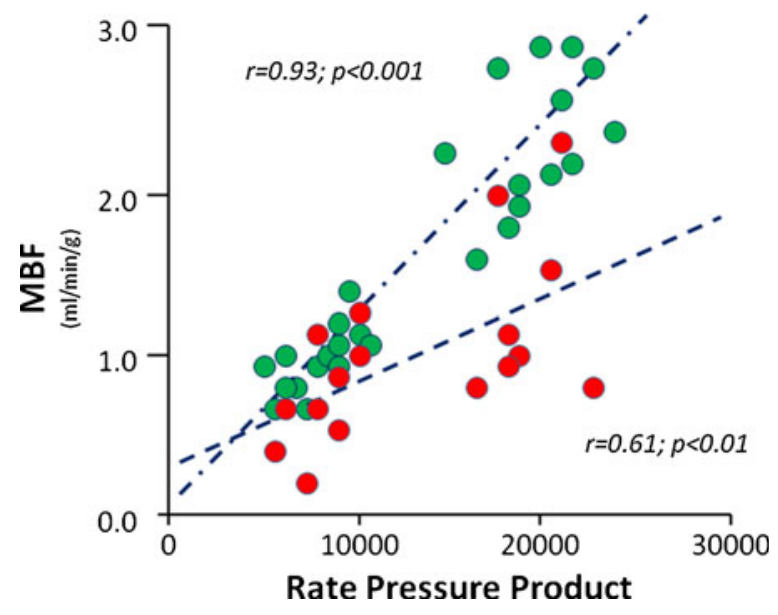

Figure 2. Relationship of myocardial blood flow to cardiac work as reflected by the rate pressure product. Myocardial blood flow was measured with N-13 ammonia at baseline and again during intravenous dobutamine infusion. Regional myocardial blood flows in myocardial territories supplied by nondiseased vessels are shown in green. In contrast, regional myocardial blood flows in territories subtended by diseased coronary vessels are shown in red. Adopted from Krivokapich et al. ${ }^{34}$

cells closely interact with vascular smooth muscle cells in order to adjust the vessel diameter to changes in flow velocities ("flow-mediated dilation"), both at the level of the microvessels and the epicardial conduit vessels (Figure 3)..$^{25}$

Major determinants of the resistance to flow include the intra-vascular pressure, the velocity of flow, the length of the vessel and, importantly, its diameter. Applying the Hagen-Poisseuil equation, resistance to flow depends on the fourth power of the vessel diameter. High velocity flows in the epicardial conduit vessels lead to greater shear-stress on the endothelial cells, prompting an endothelium-dependent, flow-mediated dilation of the conduit vessels and thus a resetting of

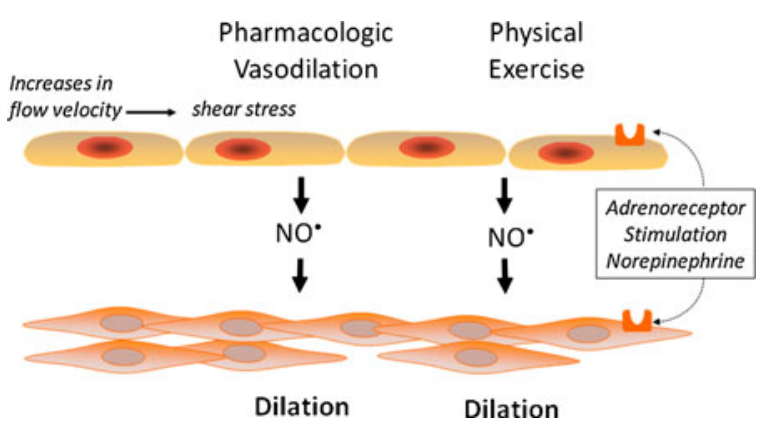

Figure 3. This highly simplified cartoon depicts the interaction between endothelial and vascular smooth muscle cells during pharmacologic vasodilation during physical stress. 
their luminal cross-sectional area in order to fully accommodate high velocity flows. This flow-mediated conduit vessel dilation, when measured on quantitative coronary angiography, serves as an index of endothelial function. Characteristically, the cross-sectional area of the vessel increases by about $20 \%$ to $30 \%$ in response to pharmacologically stimulated hyperemia. ${ }^{26,27}$ As a result of the flow-mediated vasodilation, intra-coronary pressures are fully maintained along the large epicardial coronary arteries as demonstrated with intra-coronary pressure transducers. ${ }^{28}$

Both, endothelial and vascular smooth muscle cells express adreno-receptors and thus respond to regional and systemic sympathetic stimuli. For example, local release of norepinephrine from adrenergic nerve terminals in the coronary arteries and release of catecholamines from the adrenal glands into the circulation during sympathetic stress or physical exercise lead to an $\alpha$-adreno-receptor-mediated vascular smooth muscle constriction which under normal conditions is opposed by an adrenergically-mediated release of vasodilator substances (primarily NO) from the endothelial cell. This finely tuned interaction between vasoconstrictive (mostly vascular smooth muscle dependent) and vasodilator forces (mostly endothelium related) recalibrates the vessel diameter against the flow velocity in order to maximally reduce resistance to flow (Figure 3).

Vasodilator effects of the endothelial cell are attributed here to NO as the dominant vasoactive endothelium-related substance. Actually, the endothelium releases several vasoactive substances with relaxing or constricting vascular smooth muscle effects. ${ }^{20}$ It is also important to emphasize the pivotal role of the endothelium in protecting against atherosclerosis, thrombosis, and fibrin deposition. Exposure to nonlaminar flow, modified lipoproteins, or inflammatory cytokines leads to mechanical, immunological, and chemical injury of the endothelium. Modified lipoproteins or insulin resistance for example may interfere with cellular signal transduction systems or impair receptor function, thus reducing the rate of eNOS activity and the bioavailability of NO that may be further diminished by increased rates of inactivation due to oxygen reactive species. Dysfunction and injury are associated with "endothelial activation", and loss of its atheroprotective and antithrombotic properties, when expression of adhesion molecules and production of cytokines and chemo-attractants promote the atherosclerotic process.

\section{Targets of Noninvasive Flow Measurements}

Image-based determinations of myocardial blood flows require, besides measurements of the myocardial tissue tracer concentrations and kinetics, determination of the arterial tracer input function. The latter is typically derived from serial images acquired during the initial tracer transit through the central circulation. Acquisition of this image sequence during and after the tracer administration is fundamental to most flow measurements but limits investigations of the myocardial blood flow during upright treadmill or bicycle exercise. Some studies have employed physical stress with supine bicycle exercise with the subject positioned in the imaging device. ${ }^{23,29,30}$ In general however, image-based assessments of coronary circulatory function are performed with the subject positioned in the imaging device. These assessments employ (a) pharmacological stress with vascular smooth muscle relaxing agents (as for example dipyridamole, adenosine, adenosinetriphosphate, and more recently, adenosine receptor subtype $\mathrm{A}_{2 \mathrm{~A}}$ agonists like regadenosone $)^{31-33}$; (b) pharmacologic inotropic stimulation (with for example intravenous dobutamine $)^{34,35}$; and (c) sympathetic stimulation with cold pressor testing. ${ }^{36}$ Each type of intervention targets different components or determinants of the coronary circulation.

Vasodilator stress. Pharmacological vasodilator stress seeks to maximally lower the vascular resistance through relaxation of the vascular smooth muscle cell at the level of the microcirculation, thereby uncoupling coronary flow (supply) from myocardial work (demand). Flows during vasodilator-induced hyperemia then depend largely on the coronary driving pressure and, thus, on the arterial blood pressure, and the residual coronary resistance. Despite considerable interindividual variations, pharmacologic stress induces on average three to fivefold increases in blood flow in normal individuals with hyperemic blood flows ranging from 2 to $4 \mathrm{~mL} / \mathrm{minute} / \mathrm{g}$ (depending on the type of measurement approach, the flow tracer used, and the type of image analysis).

Maximum hyperemic flows reflect the total vasodilator capacity of the coronary circulation. Because blood flow during pharmacologically-stimulated vasodilation strongly depends on the driving pressure, the "'minimal coronary vascular resistance (CVR)', (as the ratio of mean arterial blood pressure over myocardial blood flow) serves as another index of the coronary vasodilator capacity that is however normalized to the perfusion pressure. Moreover, the coronary (or more appropriately, myocardial) flow reserve has also been accepted as another measure of the vasodilator capacity. It reflects the ratio of hyperemic over rest myocardial blood flow which limits its accuracy because the term "flow reserve", not only reflects the maximallyachieved hyperemic blood flow, but depends also on myocardial blood flow at rest. In patients with hypertension for example, flows at rest are elevated due to the 
higher myocardial work so that even when hyperemic blood flows are in the range of normal, the actual flow reserve may be diminished. Some laboratories therefore adjust resting blood flows to cardiac work by normalizing flows to the rate pressure product. The flow reserve is then reported as the ratio of hyperemic to "normalized" resting blood flows.

Vasodilator-stimulated flows also depend on extravascular resistive forces. Addition of handgrip stress or supine bicycle exercise in order to raise the coronary perfusion pressure during pharmacologic vasodilation produced decreases rather than increases of hyperemic flows by about $10 \%$ to $15 \%{ }^{29,37}$ because of an increase in extravascular resistance due to higher heart rates, systolic blood pressures, and contractility.

Although pharmacological vasodilator stress targets the vascular smooth muscle, the flow response reflects the "total integrated vasodilator capacity" of the coronary circulation. It includes the contribution of endothelium-related regulatory mechanisms. Pharmacologic inhibition of eNOS with intravenous L-NAME in young, normal volunteers significantly attenuated the hyperemic response. ${ }^{38}$ Hyperemic flows after eNOS inhibition averaged only $1.50 \pm 0.55 \mathrm{~mL} / \mathrm{minute} / \mathrm{g}$ as compared to $1.90 \pm 0.33 \mathrm{~mL} / \mathrm{minute} / \mathrm{g}$ at baseline, reflecting a $21 \%$ loss in total vasodilator capacity or an about $18 \%$ decrease in myocardial flow reserve attributed to impaired endothelium-related vasodilator forces in both, the microvessels and the conduit vessels.

Positive inotropic stimulation. Pharmacologic inotropic stimulation serves as an alternate to physical stress. Intravenous administration of dobutamine, a synthetic sympathomimetic amine with a dominant positive inotropic effect via stimulation of $\beta$ - and $\alpha$-adrenoreceptors produces significant increases in myocardial oxygen consumption $\left(\mathrm{MVO}_{2}\right)$ which are associated with commensurate increases in myocardial blood flow. Infused at a rate of $40 \mu \mathrm{g} / \mathrm{kg} / \mathrm{minute}$ in 11 normal subjects, dobutamine raised $\mathrm{MVO}_{2}$ by an average of $280 \pm 80 \%$ while myocardial blood flow increased by an average of $200 \pm 80 \% .^{35}$ The dobutamine-induced changes in $\mathrm{MVO}_{2}$ correlated closely with changes in myocardial work and, further, myocardial blood flow (Figure 2).

Sympathetic stress. Sympathetic stimulation with for example cold pressor testing more specifically targets endothelium-related determinants of the coronary circulatory function. The sympathetic response to cold exposure includes prompt increases in heart rate and systolic blood pressure together with local norepinephrine release from adrenergic nerve terminals in the coronary circulation. $^{36,39}$ The increase in myocardial work as reflected by the increase in the rate pressure product is under normal conditions associated with a proportionate increase in myocardial blood flow. ${ }^{36}$ Again, a metabolically initiated, work-related increase in flow is augmented by endothelium-related vasodilator forces. Adrenergically-mediated vasoconstrictor effects on the vascular smooth muscle are balanced by largely endothelium-related vasodilator forces affecting both the microvasculature and the epicardial conduit vessels. ${ }^{25}$ In one study in 50 normal volunteers, cold pressor testing produced an average $38 \%$ increase in rate pressure product that was associated with a $30 \%$ average rise in myocardial blood flow. ${ }^{36}$

Flow responses to cold pressor testing are reported as absolute flows during cold exposure and are compared to flows at baseline, or, as a percent flow increase from baseline to cold stimulation. Analogous to the flow reserve, such percent increase does depend on baseline blood flow. Further, use of delta MBF (mL/minute/g) as a measure of the flow response is preferable because of its lesser dependency on baseline myocardial blood flow. ${ }^{36}$

The degree of endothelium-dependent modulation of flow during sympathetic stimulation appears to correspond to the endothelium-related flow augmentation during pharmacologically stimulated hyperemia. For example, in healthy subjects without coronary risk factors, the change in vascular resistance in response to cold pressor testing was significantly correlated with the adenosine- or dipyridamole-induced decline in CVR, suggesting proportionate contributions of endotheliumrelated mechanisms to both types of flow responses (Figure 4). ${ }^{36}$

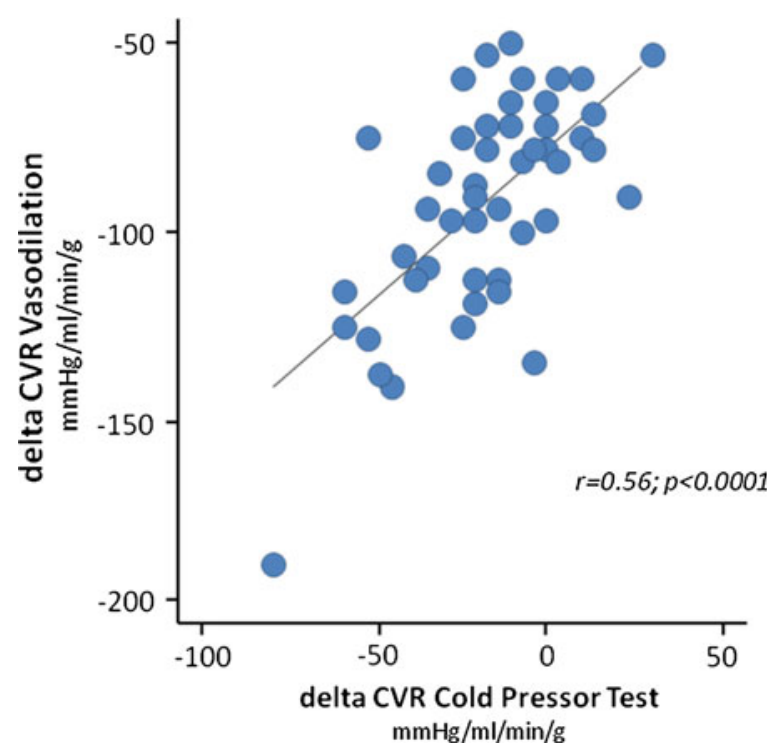

Figure 4. Changes in the CVR in response to cold pressor testing are compared to changes in the CVR during adenosine or dipyridamole stimulated hyperemia. Adopted from Prior et al. $^{36}$ 


\section{ALTERATIONS IN CORONARY CIRCULATORY FUNCTION}

Quantitative measurements of myocardial blood flow hold considerable clinical promise in several areas. They include identification of functional rather than structural disturbances that may reflect adverse effects of coronary risk factors on endothelial function or early stages of developing coronary artery disease that can signify an increased cardiac risk. Moreover, demonstration of endothelial dysfunction may identify alterations as potentially reversible in response to risk lowering therapeutic strategies so that in turn, flow measurements may also prove useful for monitoring treatment responses. Another important aspect of flow measurements is the ability to characterize extent and severity of coronary artery disease. Finally, such measurements offer a means for assessing the total ischemic burden of the myocardium due to macrovascular and microvascular disease. Assessment of the ischemic burden, as several studies have demonstrated, contains considerable prognostic information. ${ }^{17-19}$

\section{Functional Alterations Without Apparent Structural Correlates}

Investigations in asymptomatic patients with hyperlipidemia but without clinical evidence of coronary artery disease or in patients with diabetes, all with normal stress-rest perfusion images, have reported statistically significant reductions of the total integrated vasodilator capacity. ${ }^{40-43}$ This impairment, as reported by other investigations, appears wholly or partially reversible as aggressive lipid lowering treatment or glucose control in diabetic patients was associated with significant, $30 \%$ to $50 \%$ improvements in the total vasodilator capacity. ${ }^{44-48}$

Conventional coronary risk factors such as hypercholesteremia or hyperglycemia are known to adversely affect endothelial function. Improvements in coronary vasomotor function as reflected by decreases in the total vasodilator capacity and as observed after lipid- or glucose-lowering were likely due to improvements or restoration of endothelial function in the coronary conduit and resistance vessels; a possibility supported by findings of improved or even normal endotheliummediated flow responses to cold pressor testing in type 2 diabetes patients in response to glucose-lowering, possibly mediated by decreases in oxygen reactive species. ${ }^{49}$

Depending on the severity of coronary risk or the number of risk factors, functional alterations may initially remain confined to endothelium-related components without yet affecting the total integrated vasodilator capacity. For example, while the total vasodilator capacity was found to be statistically significant diminished only in patients with clinically documented type 2 diabetes as the most severe form of insulin resistance, less severe states of insulin resistance like euglycemic insulin resistance and impaired glucose tolerance were associated with normal vasodilator capacities. ${ }^{50}$ Importantly however, flow responses to sympathetic stimulation were significantly diminished even in the presence of insulin resistance alone with normal circulating glucose levels. Flow responses to cold pressor testing progressively worsened with more severe states of insulin resistance, possibly as a function of the number of risk factors. In this scenario, the normal balance between vasodilator and vasoconstrictive forces was no longer maintained. Reductions in NO bioavailability may have limited vasodilator responses so that vasoconstrictor forces, largely mediated through $\alpha$-adrenergic stimulation during cold pressor testing dominated and attenuated the normal flow response.

Disturbances in conduit vessel function. Values of hyperemic flows in individuals with risk factors for coronary artery disease are usually reported as global values, i.e., averaged over the entire left ventricular myocardium. This is important as a diminished or absent flow-related dilation of the large epicardial vessels during hyperemia can cause a progressive decline in intra-coronary pressure and thus, in myocardial perfusion along the coronary epicardial artery. ${ }^{28,51}$ Accordingly, myocardial perfusion, especially during hyperemia, progressively declines in the base-to-apex direction. Indeed, such longitudinal flow decreases have been reported in the absence of discreet coronary stenoses and in patients with conventional risk factors for coronary artery disease but without apparent clinical coronary vascular disease. ${ }^{51-53}$ In these investigations, hyperemic flows in the apical portions of the left ventricular myocardium were on average $10-20 \%$ lower than those in the basal portions (Figure 5). Hyperemic flows in the basal portion of the left ventricular myocardium may be normal but are diminished in the apical portions so that estimates of hyperemic flows when averaged of the entire myocardium may still be within the range of normal.

Different from pharmacologically-induced hyperemia where the flow-mediated vasodilation is diminished or absent, sympathetic stress may cause an actual decline in luminal diameter or "paradoxical vasoconstriction" as observed on quantitative angiography. ${ }^{27,53,54}$ Accordingly, for a constant flow but a smaller vessel lumen, resistance to flow increases and intra-coronary pressures progressively decline along the epicardial conduit vessels. The longitudinal perfusion gradient thus offers a means for assessing the epicardial 

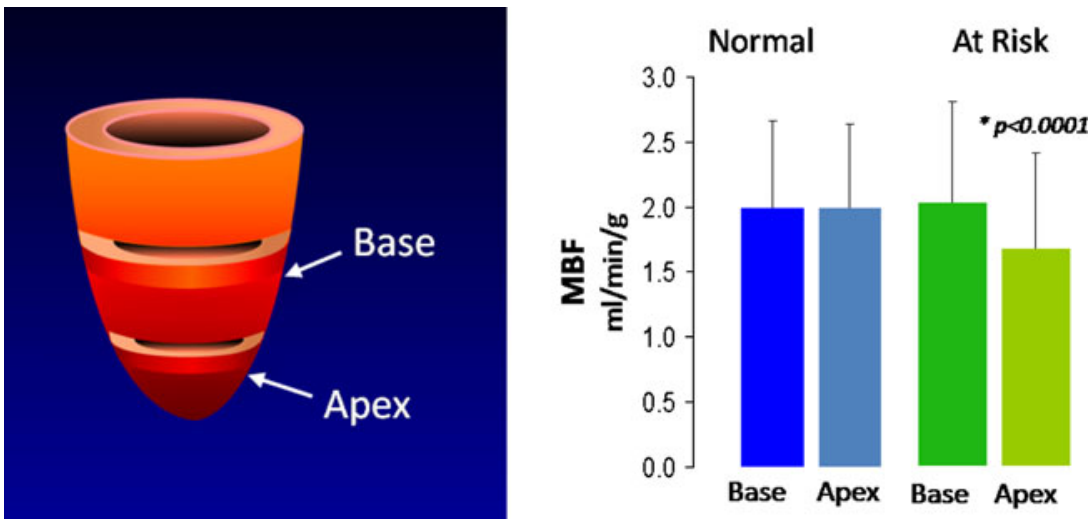

Figure 5. Longitudinal myocardial perfusion gradient during pharmacologicallystimulated vasodilation in normal volunteers without risk factors for coronary artery disease (blue) and in normal volunteers but with conventional risk factors. The panel on the left depicts a cartoon of the left ventricular myocardium and indicates the sites of blood flow measurements, with "base" for measurements in the left mid-ventricle and "apex" for measurements in the more apical portion of the let ventricular myocardium. Hyperemic flows recorded in these areas are depicted on the right; they are nearly identical in the two regions in the normal volunteers without risk factors but differ in individuals with risk factors with significantly lower flows in the apical than in the mid-ventricular region. Courtesy of Schindler et al from UCLA.

conduit vessel function. Besides endothelial dysfunctional alone, other factors such as increases in vessel stiffness, outward vascular remodeling, or diffuse luminal narrowing may account for an attenuated flowmediated dilation and, thus, for the longitudinal perfusion gradient. ${ }^{51,52}$

\section{Assessment of Extent and Severity of Coronary Artery Disease}

When fluid-dynamically significant coronary artery disease is present, the site of resistance to flow moves partially or fully from the microvessels to the epicardial conduit vessels. At rest, flow across fluid-dynamically significant stenoses is frequently maintained as long as an adequate trans-stenotic pressure gradient can be maintained by a downstream, compensatory decrease in resistance. As most or all of the microvascular resistance reserve is already spent for maintaining this transstenotic pressure gradient at rest, the vessel's ability to respond to vasodilator stimulation becomes impaired or is lost. Hence, vasodilator stress no longer elicits an adequate flow increase. The degree of impairment then depends on the stenoses severity as reported for vasodilator stress and for inotropically-stimulated myocardial work increases (Figures 2 and 6). ${ }^{34,55,56}$

While no definitive threshold values of hyperemic flows have thus far been established, myocardial flow reserves of less than 2.0 or 2.5 , based on findings with intra-coronary flow velocity probes, are now widely

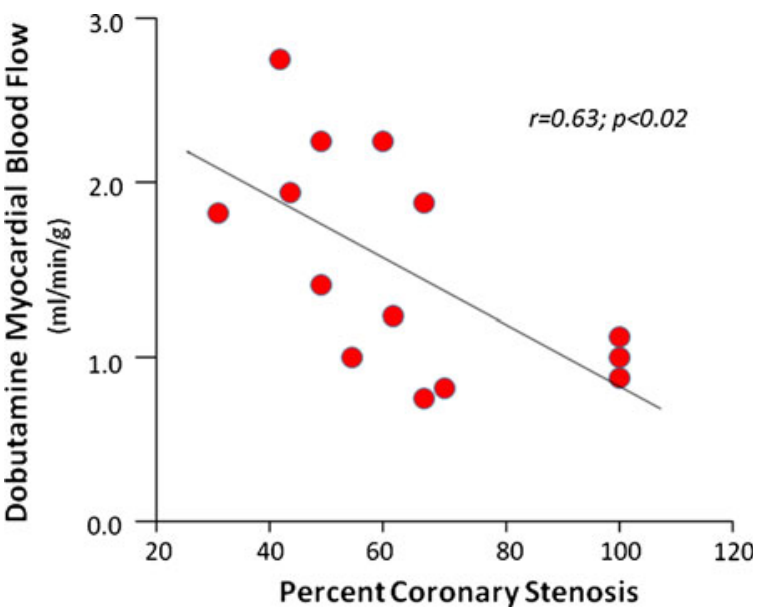

Figure 6. Inverse correlation between regional myocardial blood flow during dobutamine stress and the percent coronary diameter stenosis as determined by quantitative coronary angiography. Adopted from Krivokapich et al. ${ }^{34}$

accepted as the lower limit of normal. Applying such threshold values in patients with triple vessel disease, quantification of the myocardial flow response to hyperemic stress proved superior to standard myocardial perfusion imaging for detecting accurately the number of diseased vessels and thus the extent of coronary artery disease. ${ }^{57}$ Similar findings were reported in a more recent study where however absolute hyperemic flows rather than values of flow reserve downstream of angiographically-stenosed coronary vessels more 
accurately than myocardial flow reserve or standard perfusion imaging identified the presence of obstructive coronary artery disease. ${ }^{58}$

Flow responses to vasodilator stress in coronary artery disease may differ from those during physical exercise. Instead of an attenuated or absent flow-mediated conduit vessel dilation, physical stress may, as mentioned above, actually lead to a decrease in the vessel lumen or the stenosis diameter, possibly due to increased $\alpha$-adrenergically-stimulated smooth muscle constriction or release of vasoactive substances from the endothelium. Such vasoconstrictive effects during exercise may indeed account for the more severe perfusion defects noted in one study after physical exercise when compared to standard vasodilator stress. ${ }^{59}$

\section{Structural vs Functional Parameters of Coronary Stenoses}

Measurements of regional flow responses to vasodilator stress or inotropic stimulation can uncover and quantify the fluid-dynamic significance of stenoses. Hence, these functional measures of coronary artery disease differ from structural indices as for example percent luminal narrowing as defined MSCT coronary angiography. MSCT coronary angiography accurately identifies presence or absence of structural coronary artery disease. ${ }^{60-62}$ However, less than half of all coronary lesions defined as obstructive by MSCT are associated with stress-induced defects. ${ }^{63}$ Conversely, stress-induced flow defects are also seen in territories supplied by only mildly diseased coronary vessels on MSCT angiography. These disparate findings underscore fundamental differences between structural and functional alterations of coronary disease. The limited spatial resolution of MSCT may contribute to this disparity. ${ }^{64}$ Yet, they are also related to insufficient descriptors of structural properties of coronary stenoses. Rather than depending on only the degree of luminal narrowing, the functional significance is multifactorial and depends for example on the length of the stenosis, its eccentricity, its in- and outflow angles and surface properties. Also, functional adaptations to structural disturbances are possible. This then raises questions as to the value of functional vs structural stenosis properties for defining the cardiac risk and for predicting the long-term outcome of patients. Available follow-up data on patients, gathered over 14-16 months on average, support the accuracy of MSCT in effectively ruling out the coronary artery disease, as indicated by high event-free survivals. ${ }^{65,66}$ However, long-term follow-up studies will be needed to assess the prognostic value of structural vs functional consequences of coronary artery disease.

\section{Microvessel Disease in the Absence of Apparent Macrovascular Alterations}

Clinically most useful are measurements of myocardial blood flow in patients with angiographically nonidentifiable coronary disease or with disease confined to the microvasculature. This includes diffuse luminal narrowing without discreet coronary stenosis, ${ }^{51}$ systemic vasculopathies associated with inflammatory disorders, ${ }^{67}$ transplant vasculopathies, ${ }^{68}$ or microangiopathies as for example in diabetes, ${ }^{69}$ or in hypertrophic cardiomyopathy. ${ }^{17}$ Flow disturbances in these disorders are either functional or structural in origin or both. Even in the presence of symptoms of myocardial ischemia, due to the diffusiveness of these orders, myocardial perfusion images both at stress and rest are characteristically normal. While myocardial blood flow, when measured under resting conditions, will most likely be in the range of normal in these disorders, its response to vasodilator stress is typically diminished. In patients with type 2 diabetes for example, hyperemic flows were on average $27 \%$ lower than in a comparison group of normal volunteers (Figure 7). ${ }^{42,48}$ The degree of vasodilator impairment in these patients was related to plasma glucose levels and further, to glycemic control. Hyperemic flows in glycemically-controlled patients significantly exceeded those in poorly controlled patients. If however associated with structural microvascular disease, hyperemic responses to dipyridamole and thus to the total vasodilator capacity were found to be even more severely impaired. ${ }^{69}$

Severe restrictions in the vasodilator reserve as observed in patients with nonischemic dilated cardiomyopathy, ${ }^{18}$ with hypertrophic cardiomyopathy, ${ }^{17}$ or advanced ischemic cardiomyopathy with diminished left

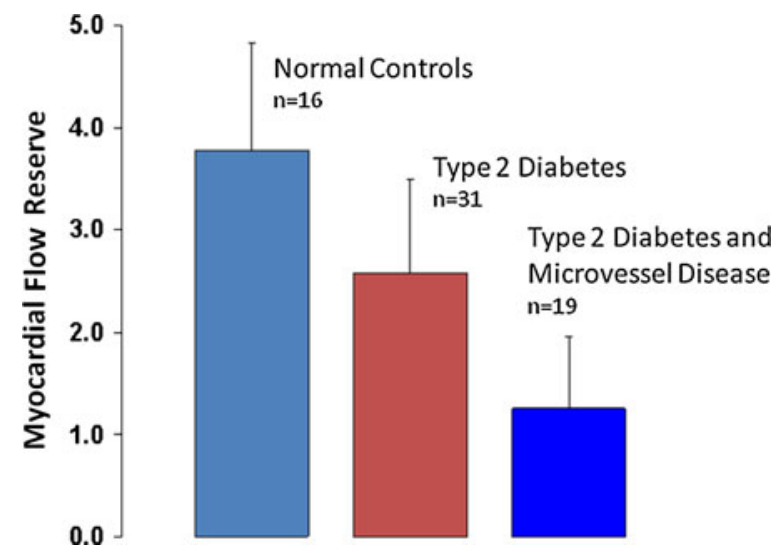

Figure 7. Myocardial flow reserve in patients with type 2 diabetes or in patients with type 2 diabetes and microvascular disease as compared to normal control individuals. Data taken from Yokoyama et al. ${ }^{42,48,69}$ 
ventricular function ${ }^{19}$ reflect the total ischemic burden. In these investigations, flow reserves of less than 1.5 were highly predictive of poor long-term outcomes in terms cardiac mortality and progression to heart failure. Even in the absence of significant macrovascular disease or coronary stenoses, the ischemic burden resulting from severe microvascular impairments equals that of a severe coronary stenosis. Using the now classic relationship between the severity of coronary stenosis and the coronary flow reserve, a myocardial flow reserve of less than 1.5 will be equivalent to an about $90 \%$ to $95 \%$ coronary stenosis. ${ }^{70}$

Increases in microvascular resistance and, thus, reductions in the total integrated vasodilator capacity can be caused by functional disturbances, by structural alterations, or by both. Functional disturbances may involve not only the endothelium but also the vascular smooth muscle, possibly as a function of the number of risk factors. ${ }^{50}$ Flow responses to interventions primarily targeting the endothelium may thus already be abnormal even though the total vasodilator capacity may still be preserved. Primarily functional disturbances may potentially be reversible as demonstrated for example after glucose-lowering in type 2 diabetes, lipid-lowering in patients with hypercholesterolemia, or administration of antioxidants. ${ }^{44-48,71,72}$ In contrast, structural alterations as the cause of microvascular impairments may involve remodeling of the intramural arterioles with thickening of the intima and media layers, as reported for hypertrophic cardiomyopathy ${ }^{73}$ increases in perivascular fibrosis and reductions in vessel density, i.e., decreases in the number of arterioles per unit mass myocardium as for example in nonischemic cardiomyopathy. ${ }^{74}$

\section{SUMMARY AND CONCLUSIONS}

It is clear now that measurements of myocardial blood flow in absolute units expand the current scope of noninvasive studies of the human circulatory function. While this new capability allows improved characterization of the extent and severity of coronary artery disease, its impact is likely to be the greatest in patients with microvascular disorders. It is in this particular disease entity where flow measurements offer a means for estimating the true ischemic burden of the myocardium and its associated cardiac risk. Further, it is in these patients, where targeting different aspects of coronary vasomotion with flow measurements can aid in determining the severity of disease, distinguish between functional and structural alterations and, at the same time, identify potential reversibility and thus therapeutic strategies. $^{71,72}$

\section{Acknowledgments}

We would like to thank Astellas Pharma US, Inc., Covidien, and GE Healthcare for corporate support to publish and distribute this article. Corporate supporters were not involved in the creation or review of information contained in this article.

\section{Open Access}

This article is distributed under the terms of the Creative Commons Attribution Noncommercial License which permits any noncommercial use, distribution, and reproduction in any medium, provided the original author(s) and source are credited.

\section{References}

1. Bergmann SR, Fox KA, Rand AL, McElvany KD, Welch MJ, Markham J, et al. Quantification of regional myocardial blood flow in vivo with h215o. Circulation 1984;70:724-33.

2. George RT, Jerosch-Herold M, Silva C, Kitagawa K, Bluemke DA, Lima JA, et al. Quantification of myocardial perfusion using dynamic 64-detector computed tomography. Invest Radiol 2007; 42:815-22.

3. Kuhle WG, Porenta G, Huang SC, Buxton D, Gambhir SS, Hansen $\mathrm{H}$, et al. Quantification of regional myocardial blood flow using $13 n$-ammonia and reoriented dynamic positron emission tomographic imaging. Circulation 1992;86:1004-17.

4. Lautamaki R, George RT, Kitagawa K, Higuchi T, Merrill J, Voicu C, et al. Rubidium-82 pet-ct for quantitative assessment of myocardial blood flow: Validation in a canine model of coronary artery stenosis. Eur J Nucl Med Mol Imaging 2009;36:57686.

5. Muzik O, Beanlands RS, Hutchins GD, Mangner TJ, Nguyen N, Schwaiger M. Validation of nitrogen-13-ammonia tracer kinetic model for quantification of myocardial blood flow using pet. J Nucl Med 1993;34:83-91.

6. Wolfkiel CJ, Ferguson JL, Chomka EV, Law WR, Labin IN, Tenzer ML, et al. Measurement of myocardial blood flow by ultrafast computed tomography. Circulation 1987;76:1262-73.

7. Christian TF, Bell SP, Whitesell L, Jerosch-Herold M. Accuracy of cardiac magnetic resonance of absolute myocardial blood flow with a high-field system: Comparison with conventional field strength. JACC Cardiovasc Imaging 2009;2:1103-10.

8. Christian TF, Rettmann DW, Aletras AH, Liao SL, Taylor JL, Balaban RS, et al. Absolute myocardial perfusion in canines measured by using dual-bolus first-pass mr imaging. Radiology 2004;232:677-84

9. Gould RG, Lipton MJ, McNamara MT, Sievers RE, Koshold S, Higgins CB. Measurement of regional myocardial blood flow in dogs by ultrafast ct. Invest Radiol 1988;23:348-53.

10. Rumberger JA, Feiring AJ, Lipton MJ, Higgins CB, Ell SR, Marcus ML. Use of ultrafast computed tomography to quantitate regional myocardial perfusion: A preliminary report. J Am Coll Cardiol 1987;9:59-69.

11. Wilke N, Simm C, Zhang J, Ellermann J, Ya X, Merkle H, et al. Contrast-enhanced first pass myocardial perfusion imaging: Correlation between myocardial blood flow in dogs at rest and during hyperemia. Magn Reson Med 1993;29:485-97. 
12. El Fakhri G, Kardan A, Sitek A, Dorbala S, Abi-Hatem N, Lahoud $\mathrm{Y}$, et al. Reproducibility and accuracy of quantitative myocardial blood flow assessment with (82)rb pet: Comparison with (13)nammonia pet. J Nucl Med 2009;50:1062-71.

13. Karamitsos TD, Leccisotti L, Arnold JR, Recio-Mayoral A, Bhamra-Ariza P, Howells RK, et al. Relationship between regional myocardial oxygenation and perfusion in patients with coronary artery disease: Insights from cardiovascular magnetic resonance and positron emission tomography. Circ Cardiovasc Imaging 2010;3:32-40.

14. Lee DC, Johnson NP. Quantification of absolute myocardial blood flow by magnetic resonance perfusion imaging. JACC Cardiovasc Imaging 2009;2:761-70.

15. Watkins $\mathrm{S}$, McGeoch $\mathrm{R}$, Lyne $\mathrm{J}$, Steedman $\mathrm{T}$, Good $\mathrm{R}$, McLaughlin MJ, et al. Validation of magnetic resonance myocardial perfusion imaging with fractional flow reserve for the detection of significant coronary heart disease. Circulation 2009;120:2207-13.

16. Nitzsche EU, Choi Y, Czernin J, Hoh CK, Huang SC, Schelbert HR. Noninvasive quantification of myocardial blood flow in humans. A direct comparison of the [13n]ammonia and the [15o]water techniques. Circulation 1996;93:2000-6.

17. Cecchi F, Olivotto I, Gistri R, Lorenzoni R, Chiriatti G, Camici PG. Coronary microvascular dysfunction and prognosis in hypertrophic cardiomyopathy. N Engl J Med 2003;349:1027-35.

18. Neglia D, Michelassi C, Trivieri MG, Sambuceti G, Giorgetti A, Pratali L, et al. Prognostic role of myocardial blood flow impairment in idiopathic left ventricular dysfunction. Circulation 2002;105:186-93.

19. Tio RA, Dabeshlim A, Siebelink HM, de Sutter J, Hillege HL, Zeebregts CJ, et al. Comparison between the prognostic value of left ventricular function and myocardial perfusion reserve in patients with ischemic heart disease. J Nucl Med 2009;50:214-9.

20. Duncker DJ, Bache RJ. Regulation of coronary blood flow during exercise. Physiol Rev 2008;88:1009-86.

21. Muller JM, Davis MJ, Chilian WM. Integrated regulation of pressure and flow in the coronary microcirculation. Cardiovasc Res 1996;32:668-78.

22. Hoffman JI. Autoregulation and heart rate. Circulation 1990; 82:1880-1

23. Krivokapich J, Smith GT, Huang SC, Hoffman EJ, Ratib O, Phelps $\mathrm{ME}$, et al. 13n ammonia myocardial imaging at rest and with exercise in normal volunteers. Quantification of absolute myocardial perfusion with dynamic positron emission tomography. Circulation 1989;80:1328-37.

24. Krivokapich J, Huang SC, Ratib O, Schelbert HR. Noninvasive detection of functionally significant coronary artery stenoses with exercise and positron emission tomography. Am Heart $\mathbf{J}$ 1991;122:202-11.

25. Schindler TH, Nitzsche EU, Olschewski M, Brink I, Mix M, Prior $\mathrm{J}$, et al. Pet-measured responses of mbf to cold pressor testing correlate with indices of coronary vasomotion on quantitative coronary angiography. J Nucl Med 2004;45:419-28.

26. Cox DA, Vita JA, Treasure CB, Fish RD, Alexander RW, Ganz P, et al. Atherosclerosis impairs flow-mediated dilation of coronary arteries in humans. Circulation 1989;80:458-65.

27. Zeiher AM, Drexler H, Wollschlager H, Just H. Modulation of coronary vasomotor tone in humans. Progressive endothelial dysfunction with different early stages of coronary atherosclerosis. Circulation 1991;83:391-401.

28. De Bruyne B, Hersbach F, Pijls NH, Bartunek J, Bech JW, Heyndrickx GR, et al. Abnormal epicardial coronary resistance in patients with diffuse atherosclerosis but "normal" coronary angiography. Circulation 2001;104:2401-6.
29. Muller P, Czernin J, Choi Y, Aguilar F, Nitzsche EU, Buxton DB, et al. Effect of exercise supplementation during adenosine infusion on hyperemic blood flow and flow reserve. Am Heart J 1994;128: 52-60.

30. Wyss CA, Koepfli P, Mikolajczyk K, Burger C, von Schulthess GK, Kaufmann PA. Bicycle exercise stress in pet for assessment of coronary flow reserve: Repeatability and comparison with adenosine stress. J Nucl Med 2003;44:146-54.

31. Chan SY, Brunken RC, Czernin J, Porenta G, Kuhle W, Krivokapich J, et al. Comparison of maximal myocardial blood flow during adenosine infusion with that of intravenous dipyridamole in normal men. J Am Coll Cardiol 1992;20:979-85.

32. Gaemperli O, Schepis T, Koepfli P, Siegrist PT, Fleischman S, Nguyen $\mathrm{P}$, et al. Interaction of caffeine with regadenoson-induced hyperemic myocardial blood flow as measured by positron emission tomography: A randomized, double-blind, placebo-controlled crossover trial. J Am Coll Cardiol 2008;51:328-9.

33. Kubo S, Tadamura E, Toyoda H, Mamede M, Yamamuro M, Magata Y, et al. Effect of caffeine intake on myocardial hyperemic flow induced by adenosine triphosphate and dipyridamole. J Nucl Med 2004;45:730-8.

34. Krivokapich J, Czernin J, Schelbert HR. Dobutamine positron emission tomography: Absolute quantitation of rest and dobutamine myocardial blood flow and correlation with cardiac work and percent diameter stenosis in patients with and without coronary artery disease. J Am Coll Cardiol 1996;28:565-72.

35. Krivokapich J, Huang SC, Schelbert HR. Assessment of the effects of dobutamine on myocardial blood flow and oxidative metabolism in normal human subjects using nitrogen-13 ammonia and carbon-11 acetate. Am J Cardiol 1993;71:1351-6.

36. Prior JO, Schindler TH, Facta AD, Hernandez-Pampaloni M, Campisi R, Dahlbom M, et al. Determinants of myocardial blood flow response to cold pressor testing and pharmacologic vasodilation in healthy humans. Eur $\mathrm{J}$ Nucl Med Mol Imaging 2007;34:20-7.

37. Czernin J, Auerbach M, Sun KT, Phelps M, Schelbert HR. Effects of modified pharmacologic stress approaches on hyperemic myocardial blood flow. J Nucl Med 1995;36:575-80.

38. Buus NH, Bottcher M, Hermansen F, Sander M, Nielsen TT, Mulvany MJ. Influence of nitric oxide synthase and adrenergic inhibition on adenosine-induced myocardial hyperemia. Circulation 2001;104:2305-10.

39. Victor RG, Leimbach WN Jr, Seals DR, Wallin BG, Mark AL. Effects of the cold pressor test on muscle sympathetic nerve activity in humans. Hypertension 1987;9:429-36.

40. Dayanikli F, Grambow D, Muzik O, Mosca L, Rubenfire M, Schwaiger M. Early detection of abnormal coronary flow reserve in asymptomatic men at high risk for coronary artery disease using positron emission tomography. Circulation 1994;90:808-17.

41. Pitkanen OP, Nuutila P, Raitakari OT, Porkka K, Iida H, Nuotio I, et al. Coronary flow reserve in young men with familial combined hyperlipidemia. Circulation 1999;99:1678-84.

42. Yokoyama I, Momomura S, Ohtake T, Yonekura K, Nishikawa J, Sasaki Y, et al. Reduced myocardial flow reserve in non-insulindependent diabetes mellitus. J Am Coll Cardiol 1997;30: 1472-7.

43. Yokoyama I, Murakami T, Ohtake T, Momomura S, Nishikawa J, Sasaki Y, et al. Reduced coronary flow reserve in familial hypercholesterolemia. J Nucl Med 1996;37:1937-42.

44. Baller D, Notohamiprodjo G, Gleichmann U, Holzinger J, Weise $\mathrm{R}$, Lehmann J. Improvement in coronary flow reserve determined by positron emission tomography after 6 months of cholesterollowering therapy in patients with early stages of coronary atherosclerosis. Circulation 1999;99:2871-5. 
45. Guethlin M, Kasel AM, Coppenrath K, Ziegler S, Delius W, Schwaiger M. Delayed response of myocardial flow reserve to lipid-lowering therapy with fluvastatin. Circulation 1999;99: 475-81.

46. Janatuinen T, Laaksonen R, Vesalainen R, Raitakari O, Lehtimaki $T$, Nuutila $P$, et al. Effect of lipid-lowering therapy with pravastatin on myocardial blood flow in young mildly hypercholesterolemic adults. J Cardiovasc Pharmacol 2001;38:561-8.

47. Yokoyama I, Momomura S, Ohtake T, Yonekura K, Yang W, Kobayakawa N, et al. Improvement of impaired myocardial vasodilatation due to diffuse coronary atherosclerosis in hypercholesterolemics after lipid-lowering therapy. Circulation 1999;100:117-22.

48. Yokoyama I, Ohtake T, Momomura S, Yonekura K, Woo-Soo S, Nishikawa $\mathbf{J}$, et al. Hyperglycemia rather than insulin resistance is related to reduced coronary flow reserve in niddm. Diabetes 1998;47:119-24.

49. Schindler TH, Facta AD, Prior JO, Cadenas J, Hsueh WA, Quinones MJ, et al. Improvement in coronary vascular dysfunction produced with euglycaemic control in patients with type 2 diabetes. Heart 2007;93:345-9.

50. Prior JO, Quinones MJ, Hernandez-Pampaloni M, Facta AD, Schindler TH, Sayre JW, et al. Coronary circulatory dysfunction in insulin resistance, impaired glucose tolerance, and type 2 diabetes mellitus. Circulation 2005;111:2291-8

51. Gould KL, Nakagawa Y, Nakagawa K, Sdringola S, Hess MJ, Haynie M, et al. Frequency and clinical implications of fluid dynamically significant diffuse coronary artery disease manifest as graded, longitudinal, base-to-apex myocardial perfusion abnormalities by noninvasive positron emission tomography. Circulation 2000;101:1931-9.

52. Hernandez-Pampaloni M, Keng FY, Kudo T, Sayre JS, Schelbert HR. Abnormal longitudinal, base-to-apex myocardial perfusion gradient by quantitative blood flow measurements in patients with coronary risk factors. Circulation 2001;104:527-32.

53. Schindler TH, Facta AD, Prior JO, Campisi R, Inubushi M, Kreissl $\mathrm{MC}$, et al. Pet-measured heterogeneity in longitudinal myocardial blood flow in response to sympathetic and pharmacologic stress as a non-invasive probe of epicardial vasomotor dysfunction. Eur J Nucl Med Mol Imaging 2006;33:1140-9.

54. Nabel EG, Ganz P, Gordon JB, Alexander RW, Selwyn AP. Dilation of normal and constriction of atherosclerotic coronary arteries caused by the cold pressor test. Circulation 1988;77:43-52.

55. Di Carli M, Czernin J, Hoh CK, Gerbaudo VH, Brunken RC, Huang SC, et al. Relation among stenosis severity, myocardial blood flow, and flow reserve in patients with coronary artery disease. Circulation 1995;91:1944-51.

56. Uren NG, Melin JA, De Bruyne B, Wijns W, Baudhuin T, Camici PG. Relation between myocardial blood flow and the severity of coronary-artery stenosis. N Engl J Med 1994;330:1782-8.

57. Parkash R, deKemp RA, Ruddy TD, Kitsikis A, Hart R, Beauchesne $\mathrm{L}$, et al. Potential utility of rubidium 82 pet quantification in patients with 3 -vessel coronary artery disease. J Nucl Cardiol 2004;11:440-9.

58. Hajjiri MM, Leavitt MB, Zheng H, Spooner AE, Fischman AJ, Gewirtz H. Comparison of positron emission tomography measurement of adenosine-stimulated absolute myocardial blood flow versus relative myocardial tracer content for physiological assessment of coronary artery stenosis severity and location. JACC Cardiovasc Imaging 2009;2:751-8.

59. Chow BJ, Beanlands RS, Lee A, DaSilva JN, deKemp RA, Alkahtani A, et al. Treadmill exercise produces larger perfusion defects than dipyridamole stress $\mathrm{n}-13$ ammonia positron emission tomography. J Am Coll Cardiol 2006;47:411-6.
60. Budoff MJ, Dowe D, Jollis JG, Gitter M, Sutherland J, Halamert E, et al. Diagnostic performance of 64-multidetector row coronary computed tomographic angiography for evaluation of coronary artery stenosis in individuals without known coronary artery disease: Results from the prospective multicenter accuracy (assessment by coronary computed tomographic angiography of individuals undergoing invasive coronary angiography) trial. J Am Coll Cardiol 2008;52:1724-32.

61. Meijboom WB, Meijs MF, Schuijf JD, Cramer MJ, Mollet NR, van Mieghem CA, et al. Diagnostic accuracy of 64-slice computed tomography coronary angiography: A prospective, multicenter, multivendor study. J Am Coll Cardiol 2008;52:2135-44.

62. Miller JM, Rochitte CE, Dewey M, Arbab-Zadeh A, Niinuma H, Gottlieb I, et al. Diagnostic performance of coronary angiography by 64-row ct. N Engl J Med 2008;359:2324-36.

63. van Werkhoven JM, Schuijf JD, Gaemperli O, Jukema JW, Boersma E, Wijns W, et al. Prognostic value of multislice computed tomography and gated single-photon emission computed tomography in patients with suspected coronary artery disease. J Am Coll Cardiol 2009;53:623-32.

64. Leber AW, Becker A, Knez A, von Ziegler F, Sirol M, Nikolaou $\mathrm{K}$, et al. Accuracy of 64-slice computed tomography to classify and quantify plaque volumes in the proximal coronary system: A comparative study using intravascular ultrasound. J Am Coll Cardiol 2006; 47:672-7.

65. Gaemperli O, Valenta I, Schepis T, Husmann L, Scheffel H, Desbiolles L, et al. Coronary 64-slice ct angiography predicts outcome in patients with known or suspected coronary artery disease. Eur Radiol 2008;18:1162-73.

66. Pundziute G, Schuijf JD, Jukema JW, Boersma E, de Roos A, van der Wall EE, et al. Prognostic value of multislice computed tomography coronary angiography in patients with known or suspected coronary artery disease. J Am Coll Cardiol 2007;49:6270.

67. Schindler TH, Nitzsche EU, Olschewski M, Magosaki N, Mix M, Prior JO, et al. Chronic inflammation and impaired coronary vasoreactivity in patients with coronary risk factors. Circulation 2004;110:1069-75.

68. Kofoed KF, Czernin J, Johnson J, Kobashigawa J, Phelps ME, Laks $\mathrm{H}$, et al. Effects of cardiac allograft vasculopathy on myocardial blood flow, vasodilatory capacity, and coronary vasomotion. Circulation 1997;95:600-6.

69. Yokoyama I, Yonekura K, Ohtake T, Yang W, Shin WS, Yamada $\mathrm{N}$, et al. Coronary microangiopathy in type 2 diabetic patients: Relation to glycemic control, sex, and microvascular angina rather than to coronary artery disease. J Nucl Med 2000;41:978-85.

70. Gould KL, Lipscomb K, Hamilton GW. Physiologic basis for assessing critical coronary stenosis. Instantaneous flow response and regional distribution during coronary hyperemia as measures of coronary flow reserve. Am J Cardiol 1974;33:87-94.

71. Campisi R, Czernin J, Schoder H, Sayre JW, Schelbert HR. $\mathrm{L}$-arginine normalizes coronary vasomotion in long-term smokers. Circulation 1999;99:491-7.

72. Schindler TH, Nitzsche EU, Munzel T, Olschewski M, Brink I, Jeserich $\mathrm{M}$, et al. Coronary vasoregulation in patients with various risk factors in response to cold pressor testing: Contrasting myocardial blood flow responses to short- and long-term vitamin c administration. J Am Coll Cardiol 2003;42:814-22.

73. Maron BJ, Epstein SE, Roberts WC. Hypertrophic cardiomyopathy and transmural myocardial infarction without significant atherosclerosis of the extramural coronary arteries. Am J Cardiol 1979;43:1086-102.

74. Camici PG, Crea F. Coronary microvascular dysfunction. N Engl J Med 2007;356:830-40. 